\title{
Place Cells, Head Direction Cells, and the Learning of Landmark Stability
}

\author{
James J. Knierim, Hemant S. Kudrimoti, and Bruce L. McNaughton \\ Arizona Research Laboratories, Division of Neural Systems, Memory, and Aging, University of Arizona, Tucson, \\ Arizona 85724
}

Previous studies have shown that hippocampal place fields are controlled by the salient sensory cues in the environment, in that rotation of the cues causes an equal rotation of the place fields. We trained rats to forage for food pellets in a gray cylinder with a single salient directional cue, a white card covering $90^{\circ}$ of the cylinder wall. Half of the rats were disoriented before being placed in the cylinder, in order to disrupt their internal sense of direction. The other half were not disoriented before being placed in the cylinder; for these rats, there was presumably a consistent relationship between the cue card and their internal direction sense. We subsequently recorded hippocampal place cells and thalamic head direction cells from both groups of rats as they moved in the cylinder; between some sessions the cylinder and cue card were rotated to a new direction. All rats were disoriented before recording. Under these conditions, the cue card had much weaker control over the place fields and head direction cells in the rats that had been disoriented during training than in the rats that had not been disoriented. For the former group, the place fields often rotated relative to the cue card or completely changed their firing properties between sessions. In all recording sessions, the head direction cells and place cells were strongly coupled. It appears that the strength of cue control over place cells and head direction cells depends on the rat's learned perception of the stability of the cues.

[Key words: place cells, head direction cells, landmark learning, path integration, hippocampus, direction sense, spatial learning]

The spatially selective firing properties (place fields) of rat hippocampal pyramidal cells (place cells) have been shown to be controlled by the salient sensory cues in the environment (O'Keefe and Conway, 1978; Muller and Kubie, 1987; O'Keefe and Speakman, 1987). Rodents can use the spatial information provided by visual cues to navigate (e.g., Collett et al., 1986; O'Keefe and Speakman, 1987), but they also can keep track of

Received May 17, 1994; revised Aug. 18, 1994; accepted Scpt. 7, 1994.

We thank J. Bliss, L. Church, C. Duffield, and M. Galganski for help with animal training and recording; $\mathrm{R}$. D'Monte for help with histology; and $\mathrm{M}$. Wilson, W. Skaggs, and M. Williams for analysis software and computer support. This research was supported by PHS Grant NS20331 from NINDS and N0014-90-J-1869 from ONR to B.L.M., the Human Frontiers Science Program, PHS Grant NS09052 from NINDS to J.J.K., and a McDonnell-Pew Program Grant to the University of Arizona.

Correspondence should be addressed to James J. Knierim, Ph.D., University of Arizona, ARI, Division of Neural Systems, Memory, and Aging, Life Sciences North Building, Room 384, Tucson, AZ 85724.

Copyright (C) 1995 Society for Neuroscience $0270-6474 / 95 / 151648-12 \$ 05.00 / 0$ their own movements and position in an environment free of polarizing cues, through vestibular and proprioceptive information (e.g., Mittelstaedt and Mittelstaedt, 1980; Etienne, 1992). One component of this path integration ability is an internal sense of direction, presumably mediated by cells that respond when the rat faces a particular direction, regardless of the spatial location of the animal. These "head direction" cells have been recorded in the postsubiculum (Taube et al., 1990a,b), posterior cortex (Chen et al., 1994a,b), thalamus (Taube, 1992; Mizumori and Williams, 1993), and striatum (Wiener, 1993). Like place cells, they can be controlled by the salient cues in the environment (Taube et al., 1990b), but they also can maintain their directional tuning in an environment free of polarizing cues (Mizumori and Williams, 1993). This system could act as an internal compass, allowing the rat to maintain an internal sense of direction in the absence of external sensory input.

Some studies of spatial learning have attempted to minimize the influence of path integration and force the use of visual cues to solve a task by intentionally disorienting the subject before each trial (e.g., Cheng, 1986; Biegler and Morris, 1993). However, McNaughton et al. (1991) hypothesized that visual cues exert control over the direction sense only after the rat has learned a stable mapping between the visual information and the head direction information. According to their model, the primary drive of the direction sense in a novel environment is the vestibular system, which is prone to cumulative error. During exploration, however, associations are formed between stable visual cues and the direction sense, such that, in a familiar environment, the rat can reset its internal compass when it drifts out of calibration by taking visual "fixes" of the environment. A disoriented rat will be unable to form strong associations, because there will be no consistent relationship between the visual cues and the rat's direction sense. Thus, the cues should have less control over the direction sense of a disoriented rat than of a rat that is not disoriented.

To test this hypothesis, we trained two groups of rats to forage for food in a high-walled cylinder with one salient visual cue. One group was disoriented before each training trial. We then disoriented both groups of rats and recorded place cells and head direction cells simultaneously to test for cue control over the direction sense and to see whether each type of cell would be affected similarly by the disorientation procedure.

Part of this research has been reported previously in preliminary form (Knierim et al., 1993; McNaughton et al., 1994).

\section{Materials and Methods}

Training protocol

Ten adult, male, Fischer-344 rats were placed on a controlled diet and maintained at approximately $80 \%$ of their free-feeding weight. The rats 
had free access to water. They were trained to search for chocolate pellets tossed randomly within a gray-walled cylinder $(51 \mathrm{~cm}$ high, 76 $\mathrm{cm}$ diameter; Muller et al., 1987); at any given time there were approximately $1-5$ pellets scattered on the floor. $\Lambda$ single white cue card covered $90^{\circ}$ of the eastern wall of the cylinder. Rats usually had two 15 min training sessions a day until they spent most of their time within the cylinder in constant motion; this took 1-4 weeks. Brown paper covered the floor of the cylinder and was replaced before each training and recording session. Rats were not allowed to sit still for long periods or to groom in the cylinder.

Disorientation training. Half of the rats underwent a disorientation procedure before each training session. The intent of this procedure was to disrupt the rat's internal sense of direction so that the cue card was the only available directional reference. Rats were taken from their home cage to a holding platform in another room, where they stayed in between training and recording sessions. Before each session, the rat was placed in a large $(28 \mathrm{~cm} \times 48 \mathrm{~cm} \times 29 \mathrm{~cm}$ high $)$ covered styrofoam box and carried up and down the hall in an irregular fashion; the box was occasionally rotated gently. The rat was then brought into the recording room, and the door between the recording room and computer control room was closed. A black circular curtain (3.66 m diameter) just inside the perimeter of the room was closed completely. The experimenter carried the rat around the cylinder a number of times, changing direction frequently and occasionally rotating the box. The experimenter carried a radio playing static noise in his pocket, in order to mask auditory cues. The box was placed into the cylinder at one of the four cardinal directions (north, east, south, or west) chosen at random, with the exception that two consecutive sessions could not have the same entry point. The rat was taken out of the box and placed on top of the box for a few seconds before being placed in the cylinder. The box was removed, and the experimenter began to toss the pellets in the cylinder. The experimenter walked around the cylinder so as not to become a stable directional reference himself. A $64 \mathrm{~cm}$ diameter circle of 100 small white Christmas tree lights, centered $160 \mathrm{~cm}$ over the cylinder floor, provided the only illumination in the black room. These conditions provided very little directional information other than the cue card; even the experimenters at times became disoriented after some time in the room, opening the curtain at the wrong location at the end of the session when trying to find the door. After $15 \mathrm{~min}$, the rat was placed back in the box from the same entry direction, and the whole disorientation procedure was repeated in reverse.

Nondisorientation training. The other half of the rats did not undergo the disorientation procedure. These rats were carried from the holding platform directly into the recording room, held openly in the experimenter's arms, and placed directly into the cylinder at one of four directions chosen at random (as above). The door and curtain between the recording and control rooms were left open, such that the rat could hear any noise coming through the doorway, and no static noise was played. Otherwise, the environment was identical to the disoricntation training environment. The objective of this training was to maintain perceptual constancy between the recording environment and the external world, such that the rat learned that the cue card was always in the same location and was thus a stable directional reference.

Immobilization training. Foster et al. (1989) showed that hippocampal pyramidal cells shut off almost completely when a rat is restrained. After the end of the primary study, we tested the effects of restraint on thalamic head direction cells in five rats. Over the course of many days, rats were trained to accept restraint by wrapping them in a towel with towel clips and Vetwrap bandage; as the wrapping became tighter over days, the rats learned that escape was impossible and they began to cease struggling. They were fed chocolate pellets as a reward for not struggling. On the recording day, rats sat on a narrow pedestal that could bc rotated, and the head dircction tuning profile was measured as the rat was slowly rotated about 10 times over the course of approximately $1 \mathrm{~min}$. The rat was then wrapped in the towel and the tuning curve was again measured. Finally, the rat was unwrapped and the tuning curve was measured once again.

\section{Recording methods}

Surgery. Recording electrodes made of four thin wires twisted together ("tetrodes"; McNaughton et al., 1983a; Kecce and O'Keefe, 1989; Wilson and McNaughton, 1993) were implanted bilaterally in each rat after it had learned to spend most of its time in the cylinder searching for food. The detailed surgical procedures are similar to those described in McNaughton et al. (1989a), with some modifications. Rats were anes-
Table 1. Standard sequence of recordings for main experiment

\begin{tabular}{lllll}
\multicolumn{5}{l}{ Cue card direction } \\
\cline { 2 - 5 } & Session 1 & Session 2 & Session 3 & Session 4 \\
\hline 1 & East & East & East & East \\
2 & East & North & East & South \\
3 & East & West & East & North \\
4 & East & East & East & East \\
\hline
\end{tabular}

thetized with pentobarbital sodium (Nembutal; $40 \mathrm{mg} / \mathrm{kg}$ i.p.), supplemented with methoxyflurane (Metofane) as necessary. They received 30,000 units penicillin (Bicillin) intramuscularly in each hind limb as a prophylactic. Two tetrodes separated by approximately $300 \mu \mathrm{m}$ were implanted in each hemisphere. The tetrodes on the right hemisphere were positioned to encounter dorsal CAl and the tetrodes on the left hemisphere were positioned to encounter the anterior thalamus. The electrodes were initially implanted $1-1.5 \mathrm{~mm}$ into the cortex. After surgery, the rats recovered in an incubator and were administered $25 \mathrm{mg}$ acetaminophen orally for analgesia. They also received $2.67 \mathrm{mg} / \mathrm{ml}$ acetaminophen in their drinking water for the next $3 \mathrm{~d}$.

Electronics. After 2-7 d of recovery, the tetrodes were advanced through the brain over the course of 3-6 d until stable units were well isolated from CA1 (2-2.5 mm below putative brain surface) on the right hemisphere and sometimes from anterior thalamus (4-5 $\mathrm{mm}$ below brain surface) on the left hemisphere. During recording, two tetrodes could be monitored simultaneously. An array of 10 FET source followers was mounted on the rat's head, four for each tetrode and two for reference electrodes. Also mounted on the rat's head were two arrays of infrared LEDs to track the animal's position and head direction in the cylinder at $20 \mathrm{~Hz}$ (Dragon Tracker). Electrical signals were filtered between $600 \mathrm{~Hz}$ and $6 \mathrm{kHz}$ and amplified 10,000 times before being digitized at $25 \mathrm{kHz}$ and stored on a $25 \mathrm{MHz}$ 80386-based computer running customized data acquisition software. All unit isolation and data analysis were performed off line.

Recording sequence. Each rat underwent numerous recording sessions over the course of many days. Four 10-15 min sessions were usually run each day, with the white cue card either at its standard location (east) or rotated between trials. All the rats from both groups were disoriented before and after each recording session; in between sessions they rested on their holding platform in another room for 10 $20 \mathrm{~min}$ with access to water. For most analyses, we used only the first $4 \mathrm{~d}$ of recording in which stable cells were recorded for each rat. The typical sequence of recordings is shown in Table 1. Additional days of recording were analyzed for other specific purposes, and these are described in the Results.

\section{Data analysis}

Off-line unit isolation. The tetrode technique, an extension of the stereotrode technique of McNaughton et al. (1983a), allows the isolation of single units based not merely on signal amplitude, as with standard single electrodes, but on the relative amplitudes of signals recorded simultaneously at four slightly different locations, using four closely spaced electrodes. Additional waveform characteristics, such as spike duration, are also used. This technique results not only in a greater yield in the number of units isolated but also improves the quality of isolation over standard single electrode techniques (Recce and O'Keefe, 1989. Wilson and McNaughton, 1993).

Waveform characteristics, such as amplitude, were plotted as a scatter plot of one of the electrodes versus another. Individual units formed clusters of points on such scatter plots, and the boundaries of these clusters were defined with the use of a custom interactive program running on a Sun Sparcstation. The spike times of individual units were then combined with the position and direction information provided by the tracker to generate fining rate maps (see Fig. 1 legend) and head direction tuning curves for each cell.

Weighted mean rotations of place cells. To determine whether place fields were bound to the cue card or whether they rotated with respect to the card between sessions, we calculated a mean rotation score of all the cells recorded in each session. For each cell, the firing rate map for one session was correlated with its firing rate map for the following session. The maps were then rotated with respect to each other in $5^{\circ}$ 
steps, and the correlation was measured for each step. The angle of highest correlation was taken as the amount of rotation for that cell. Since there were usually multiple cells recorded each day, the amount of rotation between trials was calculated as a weighted mean of all complex-spike cells meeting inclusion criteria (see below) by the following formula (adapted from Batschelet, 1981):

$$
\text { mean rotation }= \begin{cases}\arctan (\bar{Y} / \bar{X}) & \text { if } \bar{X}>0 \\ \arctan (\bar{Y} / \bar{X}) \quad 1 \quad 180^{\circ} & \text { if } \bar{X}<0,\end{cases}
$$

where

$$
\bar{Y}=\frac{\sum w_{i}\left(\sin \theta_{i}\right)}{\sum w_{i}}
$$

and

$$
\bar{X}=\frac{\sum w_{i}\left(\cos \theta_{i}\right)}{\sum w_{i}},
$$

where $w_{i}$ is the weight score for cell $i$ and $\theta_{i}$ is the angle of best correlation for cell $i$.

The weight score was intended to ensure that cells with well defined place fields at the edges of the cylinder have more weight in the overall mean rotation score than cells with poor place fields in the middle of the cylinder. It was defined as

$$
w_{i}=\text { info }_{i}\left(r_{\text {best }}-r_{180}\right),
$$

where $r_{\text {best }}$ is the highest correlation score for the rotation analysis, $r_{180}$ is the correlation score for the angle $180^{\circ}$ away from the best, and info is a measure of the amount of information about the rat's position conveyed by the firing of a single spike from the cell (Skaggs et al., 1993):

$$
\text { info }_{i}=\sum_{j} p_{j} \frac{\lambda_{j}}{\lambda} \log _{2} \frac{\lambda_{j}}{\lambda},
$$

where, if the cylinder is divided into square bins, $\mathbf{p}_{j}$ is the probability of the rat occupying bin $j, \lambda_{j}$ is the mean firing rate for bin $j$, and $\lambda$ is the mean overall firing rate for the whole cylinder. The information score is a good measure of whether a cell has a statistically significant spatial firing bias. In general, the score correlates well with the experimenter's subjective judgments of the quality of a place field. Cells whose information score was not significant at the $0.01 \mathrm{levcl}$ in both sessions were omitted from the analysis, as were cells that fired less than 50 spikes over the whole recording session.

The difference between the two opposite correlation scores $\left(r_{\text {hest }}-\right.$ $r_{180}$ ) ensured two goals: that cells with stable place fields between sessions would have more weight than cells that changed firing properties between sessions (as their $r_{\text {best }}$ score would be higher) and that cells with fields in the center would have low weight (as their $r_{\text {best }}$ score would be canceled by their $r_{180}$ score, whereas a good field at the edge would have a low or negative $r_{180}$ score, thereby enhancing its overall correlation score). In general, the weighted mean rotation score correlated well with the experimenter's subjective judgments of the overall amount of rotation of the hippocampal place representation in between trials.

Weighted variance of place cell rotation. To determine the variance in the amount of rotation between simultaneously recorded place cells, we used the following equation for variance (adapted from Batschelet, 1981), incorporating the sane weight scores described above:

$$
s^{2}=\frac{\sum 2 w_{i}\left[1-\cos \left(\theta_{i}-\bar{\theta}\right)\right]}{\sum w_{i}},
$$

where $w_{i}$ is the weight for cell $i, \theta_{i}$ is the angle of rotation for cell $i$, and $\bar{\theta}$ is the mean weighted rotation for all cells recorded at the time.

\section{Histology}

At the end of the experiments, most rats were given small electrolytic lesions to aid in determining electrode positions. Rats were perfused transcardially with $4 \%$ formalin, after which the brains were removed and placed in a $30 \%$ sucrose formalin solution until they equilibrated. Forty micron sections were cut on a sliding microtome, mounted on slides, and stained with Cresyl violet, to reconstruct electrode tracks.

\section{Results}

These results are based on a total of 329 recording sessions in 10 rats, five in each group, with each rat undergoing usually four sessions per day. We analyzed on average 3.2 complexspike cells (pyramidal cells; Ranck, 1973) per session (range 111). This number does not reflect the many recorded cells not analyzed in detail, namely theta cells (inhibitory interneurons; Ranck, 1973) and complex-spike cells that did not meet our analysis criteria (see Materials and Methods). The number is also not indicative of the total number of independent cells analyzed, for identical cells were recorded between sessions of the same day and often between days. The large majority of cells were from CA1, although some cells were from CA3 (and possibly dentate gyrus), as verified by electrode track reconstruction. No differences pertinent to this study were seen between CAl and CA3 cells. Of the 329 recording sessions, we recorded head direction cells from the thalamus in 125 sessions of seven rats. In 89 sessions one head direction cell was isolated, in 35 sessions two cells were isolated, and in one session three cells were isolated. Because the tetrodes were moved up and down repeatedly over many days to find head direction cells, it was difficult to determine precisely where each head direction cell was recorded. However, we estimate that the large majority of cells were recorded from the anteroventral nucleus (AVN) and the anterodorsal nucleus (ADN). There were no obvious differences between head direction cells recorded in these areas.

\section{Effect of nondisorientation training}

A typical recording day from a rat that had received prior training under the nondisorientation conditions is shown in Figure $1 A$. Three place cells (two of which are illustrated) were recorded simultaneously over four sessions, in which the cue card inside the cylinder (denoted by the black arc) was located east, west, east, and north. The rat was disoriented before each session. In each session, the place fields of both cells retained a constant position relative to the cue card. Place cell 1 had a field in the northwest quadrant of the cylinder when the cue card was east (sessions 1 and 3); when the cue card was rotated $180^{\circ}$ to the west (session 2), the field also rotated $180^{\circ}$ to the southeast quadrant; when the cue card was north, the field was in the southwest quadrant. The field of place cell 2 also rotated with the cue card. The third cell (not shown) had a ficld that was near the center of the cylinder, but it appeared to rotate with the cue card as well. These results are consistent with those reported by others (O'Keefe and Conway, 1978; Muller and Kubie, 1987; O'Keefe and Speakman, 1987), in which the salient cues had strong control over the place field locations.

\section{Effect of disorientation training}

We failed, however, to replicate the foregoing effect in the rats trained under disorientation conditions. A typical day of recording for such a rat is shown in Figure $1 B$. On this day, we recorded simultaneously six place cells (two of which are shown) and one head direction cell. In each session the cue card was located east. In the first two sessions, place cell 1 and place cell 2 had place fields located along the east and northwest walls, respectively (although the field of place cell 2 was poor in session 1). However, in session 3, the fields of both cells rotated about $135^{\circ}$ clockwise relative to the cue card, and they retained this position in session 4 . The tuning curve of the simultaneously recorded head direction cell, peaking originally at northeast, rotated by the same amount as the place fields in session 3 and 


\section{A. NONDISORIENTATION TRAINING}

Cell 1
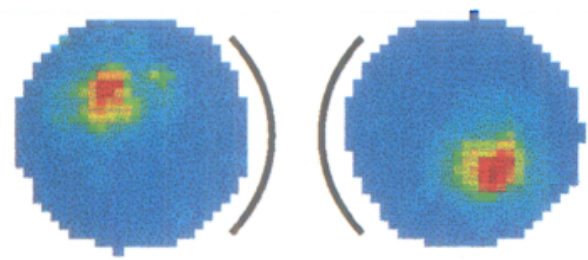

Cell 2
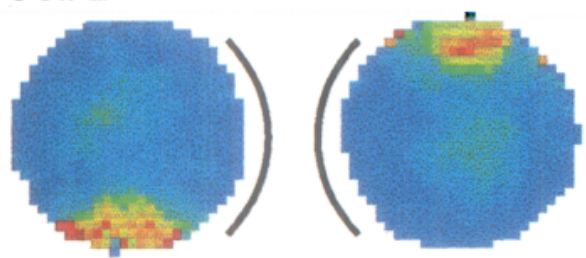

Session 1 East
Session 2
West
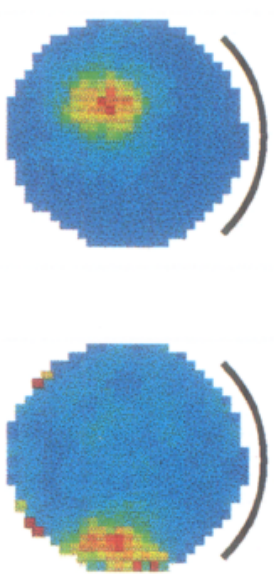

\section{Session 3} East
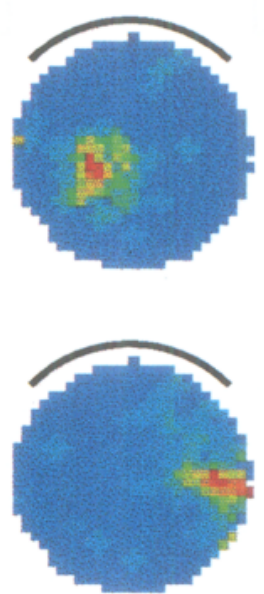

\section{Session 4 North}

\section{B. DISORIENTATION TRAINING}

\section{Cell 1}

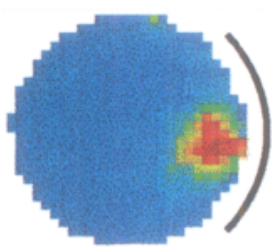

Cell 2

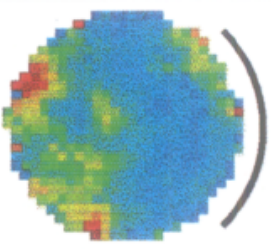

\section{CA1 Place Cells}
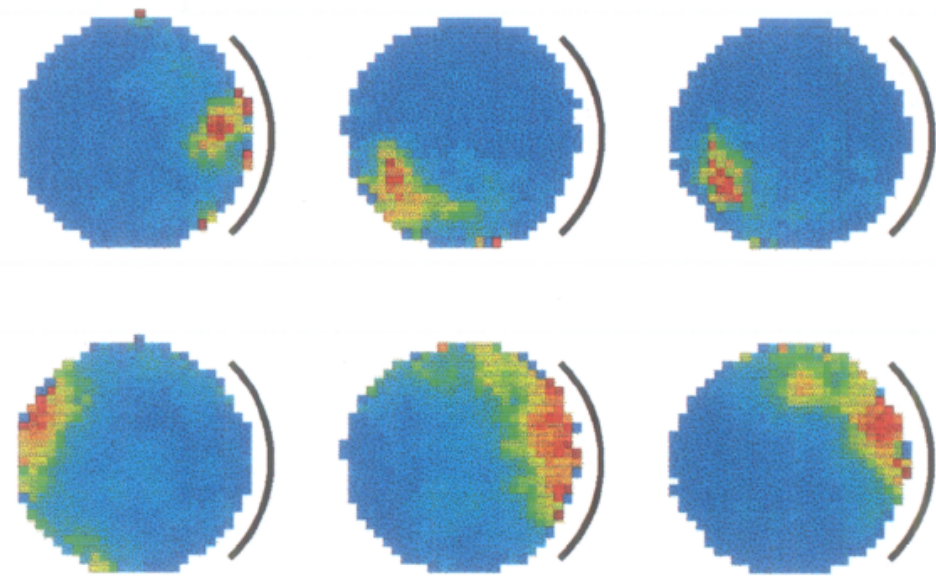

\section{Thalamic Head Direction Cell}

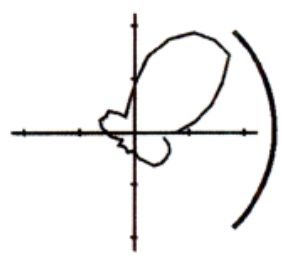

Session 1 East

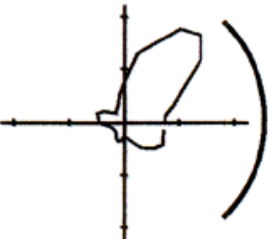

Session 2 East

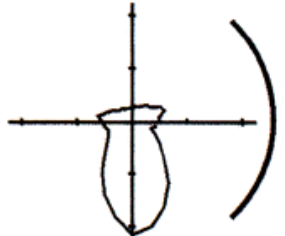

Session 3 East

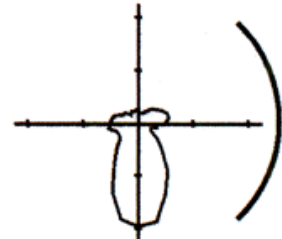

Session 4 East
Figure 1. Representative results from a rat trained under nondisorientation conditions $(A)$ and a rat trained under disorientation conditions $(B)$. Both rats underwent the disorientation procedure before recording. A, Firing rate maps of two simultaneously recorded CA1 place cells were constructed by binning the cylinder into $2.8 \mathrm{~cm}$ squares and dividing the number of times the cell fired when the rat occupied each bin by the total amount of time the rat spent in the bin. A smoothing algorithm was then applied such that the value of each bin became the average of itself and its four adjacent neighbors. The maps are color coded such that "cooler" colors represent low firing rates (blue indicates no firing) and "hotter" colors indicate high firing rates (red indicates maximal firing). The black arc represents the location of the white cue card each session, which was rotated east to west to east to north in between sessions. The place fields of both cells maintained their positions relative to the cue card in all sessions (i.e., they rotated with the cue card). Rat 3911: direction rat entered cylinder, session 1 , north; 2 , east; 3 , north; 4 , south. Maximum firing rates for cell 1 in spikes/ sec: session 1,$20 ; 2,20 ; 3,9 ; 4,2.5$. Maximum firing rates for cell 2 in spikes/sec: session 1, 24; 2, 24; 3, 18; 4 , 10. $B$, Firing rate maps of two simultaneously recorded CAl cells were constructed as above. In addition, a head direction cell from the thalamus was recorded simultaneously, and its tuning curve for each session was constructed by dividing the number of times the cell fired when the rat faced a particular direction (in bins of $10^{\circ}$ ) by the amount of time the rat faced that direction. On this day, all four sessions were run with the cue card at its standard location (east). In session 3, both place cells rotated their place fields and the head direction cell rotated its firing direction relative to the cue card (and to the external environment) by about the same amount. All three cells maintained these new firing properties in session 4. Rat 3803: direction rat entered cylinder, session 1, north; 2, south; 3 , west; 4 , east. Maximum firing rates for cell 1 in spikes/sec: session 1 , $18 ; 2,15 ; 3,8 ; 4,6$. Maximum firing rates for cell 2 in spikes/sec: session 1 , $15 ; 2,30 ; 3,30 ; 4,36$. Head direction cell axes, \pm 45 spikes/sec all four sessions. 
retained this direction in session 4 . Of the remaining four place cells recorded, three of them also rotated by about $135^{\circ}$, and the other had a field in the center of the cylinder. Note that all four sessions were identical in terms of both the controlled white cue card and any possible uncontrolled cues in the laboratory. In general, the cue card had weaker control over the place fields and head direction cells in those rats that had been trained under disorientation conditions than those rats trained under nondisorientation conditions. Moreover, the place cells and head direction cells were always strongly coupled. Over the total number of recording sessions, in every case that the place cells rotated in between sessions in relation to the cue card and in which we recorded a head direction cell simultaneously, the head direction cell also rotated by approximately the same amount (see below). Simultaneously recorded place cells were also strongly coupled to each other. We calculated the dispersion from the mean of all place cells recorded in all sessions for each training group (see Materials and Methods). The standard rotational deviation from the mean for the disorientation training rats and the nondisorientation training rats was $21.9^{\circ}$ and $15.4^{\circ}$, respectively; this difference was not significant (Mann-Whitney $U$ test). We consider these numbers to be within the range of experimental error, given the variability in place cell firing rates, location sampling, unit isolation, and remapping effects (see next section) between sessions.

\section{Head direction cells and hippocampal remapping}

In some rats, a more complicated "remapping" of the hippocampal representation occurred when the place fields and head direction cells broke away from the cue card. An example is shown in Figure 2. For this rat trained under disorientation conditions, the head direction cell rotated relative to the cue card in session 2 and rotated back to its original direction relative to the cue card in sessions 3 and 4. The hippocampal cells displayed a more complicated pattern of behavior in session 2 , in that some cells completely changed their place fields in that session. Three of the five cells recorded that day are illustrated. Place cell 1 originally had a tight field in the middle of the northeast quadrant of the cylinder in session 1 . When the head direction cell rotated relative to the cue card in session 2 , this place cell developed a completely different field along the southwest wall of the cylinder (although it still fired weakly in its original location relative to the head direction cell). In sessions 3 and 4 , when the head direction cell returned to its original direction, place cell 1 also returned to its original field. Place cell 2, which originally was silent in the first session, developed a very strong field covering the southeast wall in session 2 , but became virtually silent again in sessions 3 and 4 (although it maintained a weak remnant of its field). In contrast, place cell 3 behaved like the cells in Figure $1 B$, in that it maintained the same field in sessions 1 and 2 , but the field rotated relative to the cue card by the same amount that the head direction cell rotated. Of the remaining two cells recorded that day, one of them rotated with the head direction cell and the other probably changed its firing pattern, although this was ambiguous. The same pattern of results was observed in the cells recorded on the preceding and following days. Thus, when the head direction cells adopted a different orientation relative to the cue card, the hippocampus developed a new representation of the environment, although the new representation was not completely independent of the original. This rat was the only one that showed this effect very convincingly over a number of days, although three other rats showed some evidence of a similar remapping.

\section{Population statistics}

As seen in the examples, the cue card had greater control over the place cells and head direction cells in those rats that had received the nondisorientation training than in those rats that had received the disorientation training. This comparison is shown for all rats in Figure $3 A$. For each rat, we counted the number of times that its place fields and/or head direction cells rotated relative to the cue card by at least $45^{\circ}$ from one session to the next; these rotations were called transitions. For example, in Figure $1 B$, a transition occurred between sessions 2 and 3 , when the place fields broke away from the cue card control. Two transitions occurred in Figure 2, when the head direction cell rotated in session 2 and rotated back again in session 3 . Since this analysis is based on $4 \mathrm{~d}$ of recording with four sessions each day, the number of possible transitions for each rat was 12 (transitions between days were not counted, to avoid possible confusion between different neurons). The disorientation training rats had many more transitions than the nondisorientation training rats $(t=4.26, p=0.001$, one tailed). Thus, the extent to which the cue card controlled the locations of place fields depended strongly on the prior training history of the rat. Those rats that had previously experienced the cue card as being an explicitly stable cue had fields that were more strongly bound to the cue card than those rats that had never had this type of training.

Nevertheless, the cue control over the place fields of the nondisorientation training rats was not as strong as that reported previously in experiments under similar recording conditions (Muller and Kubie, 1987; Bostock et al., 1991). Some insight into this discrepancy is provided by determining the first recording session in which a transition occurred for each rat (Fig. $3 B)$. Two of the nondisorientation training rats experienced their first transition on the last recording session of the last day (session 16); another rat never had a transition at all (although it had fewer recording sessions than the other rats) and was assigned a maximum value of 16 . All of the disorientation training rats had their first transition by the seventh recording session, before any of the nondisorientation training rats had a transition. Thus, the cue card initially exerted strong control over the place fields in most nondisorientation training rats, but this control quickly lost strength as the rats began to experience the disorientation procedure during recording sessions, such that after only a few days of this procedure the place fields began to break away from the cue card.

Although the nondisorientation training rats had fewer transitions than the disorientation training rats, there was no difference in the magnitude of rotations for each group. On average, the fields for the nondisorientation training rats rotated $129^{\circ} \pm$ $10^{\circ} \mathrm{SE}\left(n=9\right.$, range $\left.74^{\circ}-171^{\circ}\right)$ relative to the cue card when a transition occurred, and the fields for the disorientation training rats rotated $116^{\circ} \pm 7^{\circ} \mathrm{SE}\left(n=27\right.$, range $\left.=53^{\circ}-174^{\circ}\right)$; the difference was not significant ( $t=0.949, p=0.35$, two tailed). Thus, the difference between the two groups in the strength of cue card control was manifested only as a difference in the probability of cells rotating away from the card, not as a difference in the magnitude of rotation. There were also no differences between the two groups in the mean firing rate or the mean information content (see Materials and Methods) of place cells.

Figure 4 shows a histogram of the place ficld positions relative to the cue card for the recording sessions of all disorientation 


\section{Thalamic Head Direction Cell}
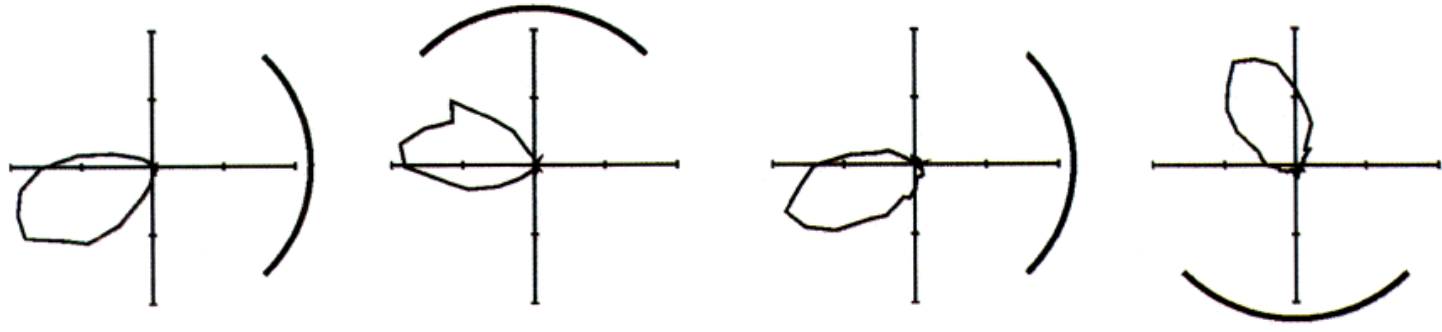

Cell 1
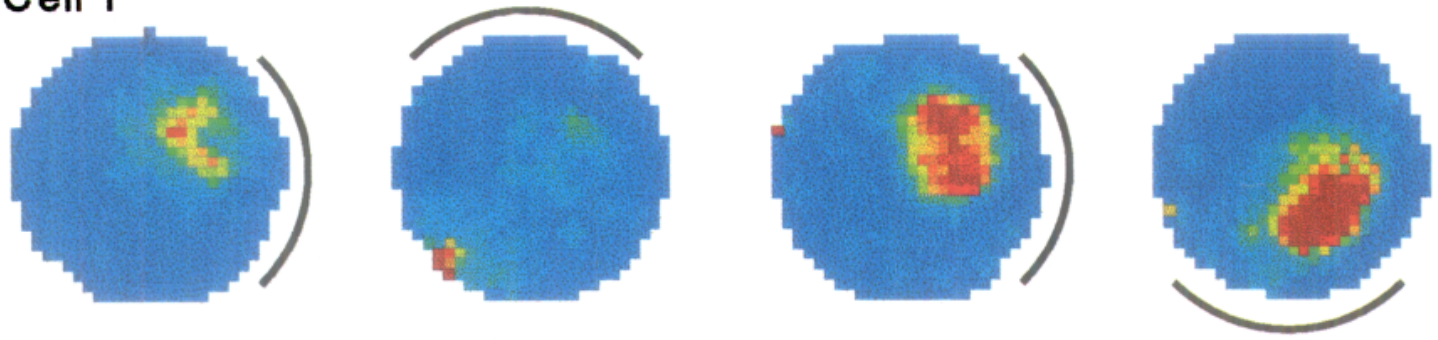

\section{Cell 2}
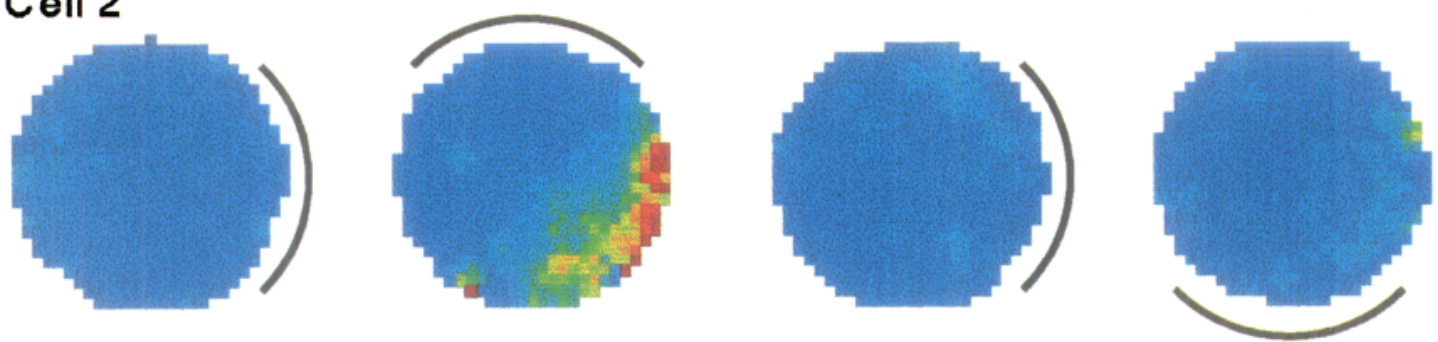

\section{Cell 3}
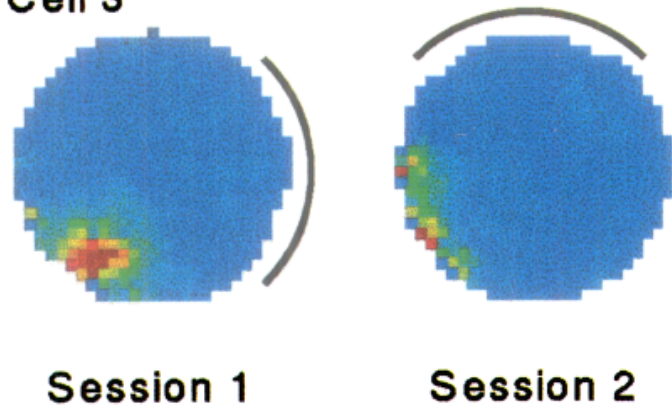

East

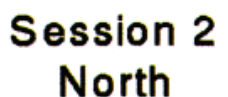

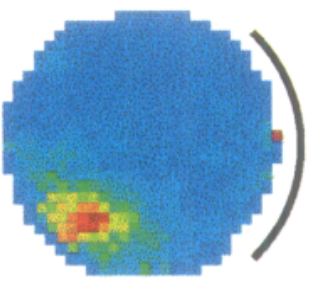
East

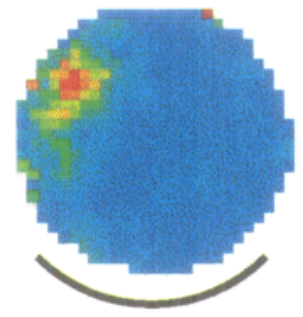

\section{Session 4 South}

Figure 2. Example of remapping of the hippocampal representation when the head direction cell rotates away from the cue card. Firing rate maps of three simultaneously recorded CA1 place cells and the head direction tuning curve of one simultaneously recorded thalamic cell were constructed as in Figure 1. The cue card was positioned east, north, east, and south in the four sessions. In sessions 1,3 , and 4, the place cells and head direction cell all remained constant relative to the cue card. In session 2 , however, when the cue card was rotated $90^{\circ}$ counterclockwise, the head direction cell rotated about $45^{\circ}$ in the opposite direction. The hippocampal cells displayed a complicated pattern of behavior, in that some cells completely changed their firing properties in that session. Cell 1 changed its place field, cell 2 gained a field, and cell 3 rotated its field along with the head direction cell. All three cells reverted back to their original firing properties in session 3. Rat 3918: direction rat entered cylinder, session 1 , north; 2, east; 3, north; 4, west. Maximum firing rates for place cell 1 in spikes/sec, all sessions, 9. Maximum firing rates for place cell 2 in spikes/sec, all sessions, 18. Maximum firing rates for place cell 3 in spikes/sec, all sessions, 12. Head direction cell axes in spikes/sec: session 1, $\pm 18 ; 2, \pm 12 ; 3, \pm 12 ; 4, \pm 10$.

training (white squares) and nondisorientation training (black squares) rats. The polar angle of the place field location relative to the cue card in session 1 was defined as the $0^{\circ}$ angle for each day. The field locations clustered around $0^{\circ}$, indicating that for most sessions the fields were anchored by the cue card in both groups of rats. In those sessions in which a transition occurred (rotation $>45^{\circ}$ ), there was no overall bias in favor of any particular degree of rotation. This analysis complements that of Fig- 

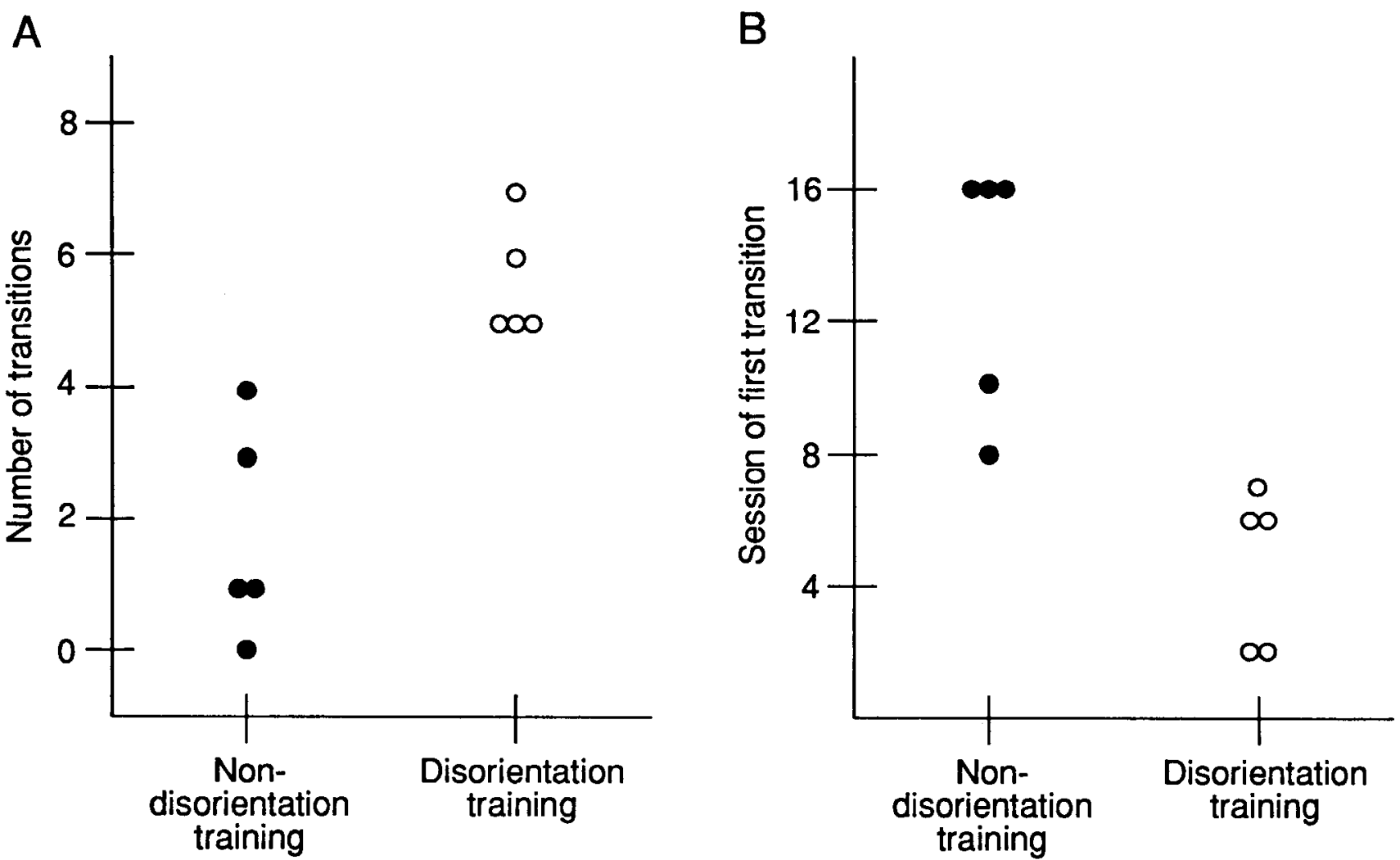

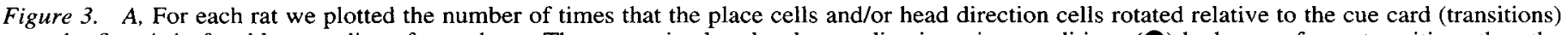

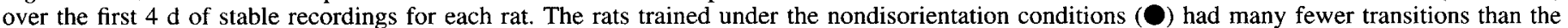

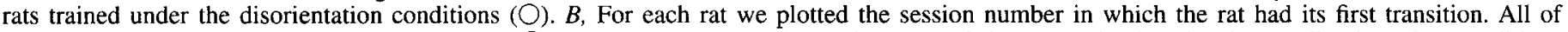

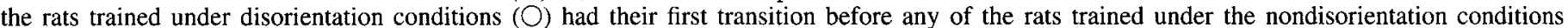

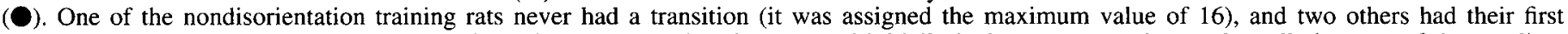

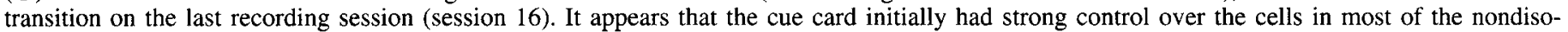
rientation training rats, but it soon lost this control as these rats began to experience the disorientation procedure during recording sessions.

ure 3 in that both figures show that there was a greater tendency for place fields to break away from the cue card in disorientation training rats than in nondisorientation training rats. Note that this effect appears stronger in Figure $3 A$ than in Figure 4 , due to differences in the method of analysis. For example, the sessions illustrated in Figure $1 B$ give rise to one transition in Figure $3 A$, but have two entries that are $>45^{\circ}$ in Figure 4 . We chose the transitions of Figure 3 as our main analysis because of the unavoidably arbitrary nature of choosing a $0^{\circ}$ reference in Figure 4.

\section{Theta cells}

In 44 sessions of seven rats, we cleanly isolated at least one theta cell in addition to the complex-spike cells and head direction cells. Although theta cells are highly active throughout a given environment, they do tend to have consistent spatial biases in their firing rates (McNaughton et al., 1983b; Kubie et al., 1990 ). We thus performed the same rotational correlation analysis on them as we did on the place cells. In all sessions, the theta cells' firing biases were bound to the place cells and the head direction cells. They followed the rotation of the cue card when the place cells did, and in the six sessions in which the place cells rotated away from the cue card, the theta cells rotated by approximately the same amount.

\section{Effects of retraining}

We retrained four of the five disorientation training rats under the nondisorientation conditions to see if the cue card would subsequently exert greater control over the place fields. Place cells and/or head direction cells were recorded during 4-6 d of retraining, with 3-4 sessions per day, and then during 2-4 test days under the disorientation conditions, with four sessions per day. The results are shown in Table 2 . Only one of the rats (3803) had improved control over the place cells by the cue card after the additional training, reducing the number of transitions from five (before retraining) to one (after retraining). The other three rats showed no improvement. Interestingly, the rat that showed improvement was the only rat that had no transitions during the retraining period, when recording was done under nondisorientation conditions. The other three rats had many transitions during the retraining period, even though they were not disoriented and the cue was always in the same location.

In two of the nondisorientation training rats, we recorded additional sessions to test how strong the cue control would be if we recorded under nondisorientation conditions, but rotated the cue card between each trial. After the initial $4 \mathrm{~d}$ of disorientation recording, we gave each rat $1 \mathrm{~d}$ of nondisorientation recording with the cue card in its standard east location in all four sessions; the fields were stable with respect to the cue card. On the next few days, we rotated the cue card between each session and recorded under nondisorientation conditions. For one rat, in seven out of eight sessions the place fields and head direction cell did not follow the rotation of the cue card, but instead maintained a constant relationship to the laboratory reference frame. 


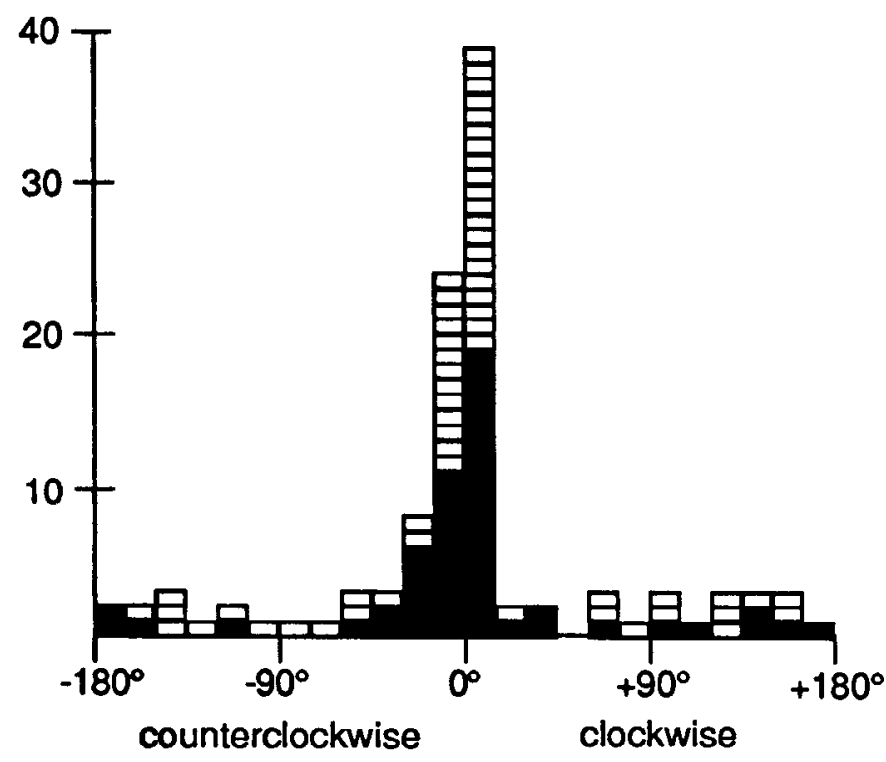

Figure 4. Place field locations relative to the cue card for the first 16 recording sessions of each rat in which stable recordings from well isolated cells were obtained. The polar angle of the place field location in the first session of each day was considered the $0^{\circ}$ angle for that day. White rectangles correspond to disorientation training rats; black rectangles correspond to nondisorientation training rats. The distribution is peaked sharply around $0^{\circ}$, demonstrating that in most sessions the fields were anchored to the cue card for both groups of rats. When the fields did rotate relative to the cue card $\left(>45^{\circ}\right)$, there was no tendency for the cells to rotate to any particular direction.

This rat also had three transitions during the disorientation recording sessions earlier, so it appears that it had already learned that the cue card was not a stable reference. For the other rat, though, the place fields followed the cue card in 10 out of 12 sessions. For this rat, the cue control was so strong that it often overrode the rat's internal direction sense even when the rat was not disoriented and could presumably tell that the card was in a different location each session. These combined results indicate that, in many rats, it is difficult to overcome the prior learning effects regarding the perceived stability of the visual cue, similar to behavioral results in hamsters reported by Etienne et al. (1993).

\section{Coupling between place cells and head direction cells}

As mentioned above, simultaneously recorded place cells and head direction cells were always strongly coupled. Figure 5 shows a scatter plot of the rotation of head direction tuning curves versus the mean rotation of simultaneously recorded place cells in between sessions, relative to the external (laboratory) coordinates, in all sessions in which both types of cells were recorded. Open squares indicate sessions in which the cells followed the rotation of the cue card; hence, they are clustered around $0^{\circ}$, $\pm 90^{\circ}$, and $\pm 180^{\circ}$. Black circles indicate sessions in which a transition occurred. In almost every case, the rotation of the head direction cells was matched by the rotation of the place cells. The one case that lies far off the diagonal is a session in which the hippocampal representation remapped, which makes the mean rotation score for the place cells unreliable. Overall, the rotational correlation coefficient for the head direction cells versus the place cells was $0.86\left(r^{2}=0.74, p<0.001\right.$; Batschelet, 1981).
Table 2. Effects of retraining Disorientation rats

\begin{tabular}{llll} 
& \multicolumn{2}{l}{ Number of transitions } \\
\cline { 2 - 4 } Rat number & $\begin{array}{l}\text { Before } \\
\text { retraining }\end{array}$ & $\begin{array}{l}\text { During } \\
\text { retraining }\end{array}$ & $\begin{array}{l}\text { After } \\
\text { retraining }\end{array}$ \\
\hline 3803 & $5 / 12$ & $0 / 10$ & $1 / 12$ \\
3917 & $6 / 12$ & $3 / 12$ & $8 / 12$ \\
3918 & $5 / 12$ & $9 / 18$ & $6 / 12$ \\
3986 & $7 / 12$ & $6 / 12$ & $3 / 6$ \\
\hline
\end{tabular}

Head direction cells and place cells in the same session

Head direction cells and place cells often rotated relative to the cue card within a given recording session. One example is shown in Figure 6. The place field of a CA1 cell and the head direction tuning curve of a thalamic cell are shown broken up into eight $1 \mathrm{~min}$ epochs. During the first minute, the head direction cell fired southeast, which was its "proper" direction relative to the cue card (based on the prior three sessions of the day). During the second and third minutes, however, it rotated about $90^{\circ}$ clockwise. It stayed at that direction for about $2 \mathrm{~min}$, then rotated back to its original southeast direction (min 5-6), where it remained stable for the rest of the $15 \mathrm{~min}$ recording session. The firing of the simultaneously recorded place cell precisely matched the rotations of the head direction cell. Thus, the cue card initially had control over the head direction cell and place cell, momentarily lost it as the two cells rotated in synchrony, and then regained control after a few minutes. This synchronous rotation of the head direction and place cells, within a recording session and on a time scale of seconds, reinforces the notion that these two systems are strongly coupled.

We also saw cases of remapping of the hippocampal representation within a recording session as the head direction cell

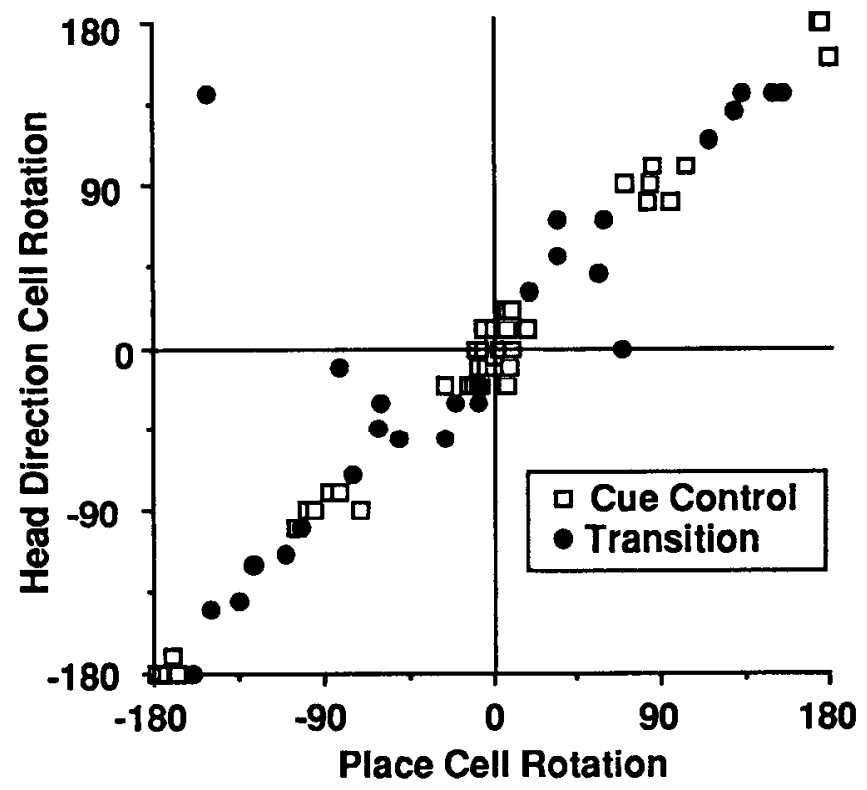

Figure 5. Scatter plot of rotations of head direction cell tuning curves in between sessions, relative to external (laboratory) coordinates, versus the place cell mean rotations, for all sessions in which both types of cells were recorded simultaneously. $\square$ indicate sessions in which the visual cue had control over the cells. indicate sessions in which a transition occurred. 


\section{CA1 Place Cell}
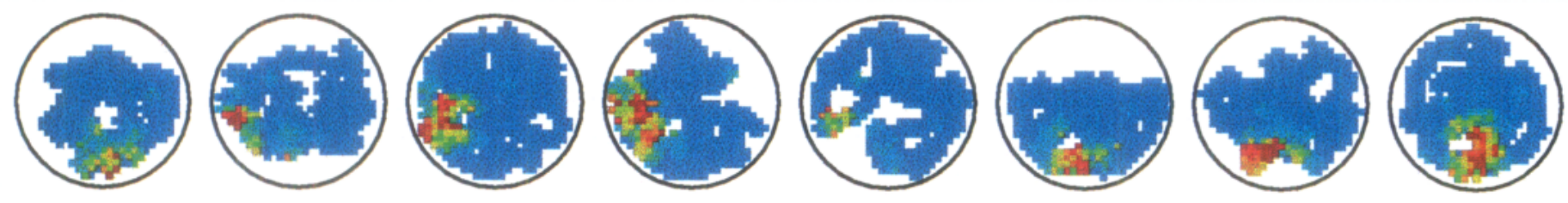

\section{Thalamic Head Direction Cell}

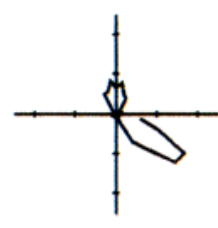

1

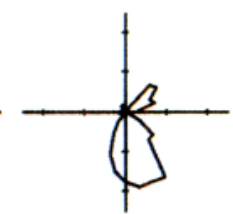

2

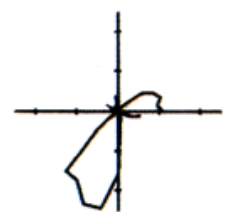

3

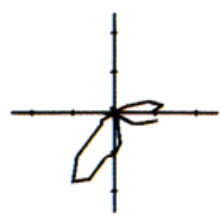

4

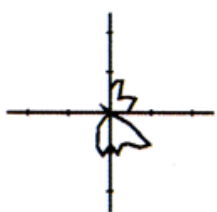

5

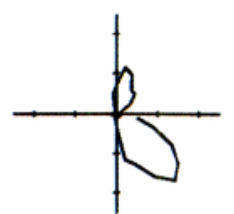

6

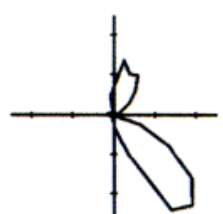

7

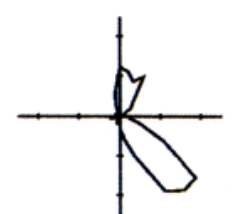

8

Minutes

Figure 6. Corotation of a CA1 place cell and a head direction cell within the same recording session. The CA1 firing rate map and the head direction tuning curve are broken down into $1 \mathrm{~min}$ segments for the first $8 \mathrm{~min}$ of the recording session. Both cells initially fired at their "correct" location/direction relative to the cue card (as determined by the previous three sessions that day). During the second and third minutes, both cells rotated approximately $90^{\circ}$ clockwise, where they stayed for about 2 min before rotating back to their original firing location/direction (sixth minute), where they stayed for the rest of the 15 min session. The white areas in the firing rate maps indicate locations that the rat did not visit within that minute. The bilobed head direction tuning curves indicate that we were probably recording two cells, which rotated together. Rat 3803 : maximum firing rate for place cell, each minute, $30 \mathrm{spikes} / \mathrm{sec}$. Head direction cell axes, each minute, $\pm 50 \mathrm{spikes} / \mathrm{sec}$.

rotated within the session. Figure 7 shows a 12 min recording session broken into thirds. The head direction cell initially fired near west for the first $4 \mathrm{~min}$. It then rotated $90^{\circ}$ counterclockwise to its "proper" direction, where it remained the rest of the session. At the same time that the head direction cell rotated, place cell 1 lost its field, whereas place cell 2 developed a field. Place cell 3, on the other hand, retained its place field the whole session, but the field rotated along with the head direction cell. Thus, even within a single recording session, we saw the same partial remapping effect seen previously between recording sessions (Fig. 2).

It was often difficult to determine unambiguously whether the place fields rotated or remapped within a given session on a minute by minute time scale, due to the rat's inadequate sampling of all positions in the cylinder in that short time period. However, a well isolated head direction cell typically provides a reliable tuning curve in less than a minute. We therefore calculated population statistics on these within-session effects only for head direction cells. Of 125 sessions, the head direction cell rotated by $30^{\circ}$ or more in at least 38 of them (30\%), not including a few ambiguous cases in which a poorly isolated cell made the tuning curve based on a minute's data unreliable. In 29/38 cases, the rotations occurred early, within the first $4 \mathrm{~min}$ of the session. The amount of rotation was quite variable, ranging from our minimum criterion of $30^{\circ}$ up to $130^{\circ}$. This maximum may be an underestimate, and the number of sessions in which the cell rotated is surely an underestimate, as it is very likely that in some sessions the head direction cell started rotating before data collection started. There were no obvious differences between disorientation training and nondisorientation training rats in the magnitude or probability of rotations within a session, although we do not have enough data on this effect from the nondisorientation training rats to make a strong comparison.
For each day of recording, we determined the most stable direction for each head direction cell relative to the cue card; in two cases this was ambiguous, because the cell had two equally stable directions. In most cases in which the head direction cell rotated within the session, it rotated from a different direction and settled in the stable direction (25/34); in six cases the head direction cell initially fired in a different direction and rotated to another direction that was still different from the stable direction; in three cases, the head direction cell started at the stable direction, rotated away from it, but then returned to the stable direction (as in Fig. 6). In no case did we see a head direction cell start at the stable direction, rotate away, and then remain at this new direction.

\section{Correlation of transitions with entry direction}

Sharp et al. (1990) showed that the locations of place fields in a visually symmetric environment usually depended on the direction from which the rat entered the apparatus. In the present study, we found no relationship between the probability of a transition and the absolute entry direction of the rat, the absolute direction of the cue card, or the entry direction of the rat relative to the cue card. For example, a transition was equally likely to occur if the rat entered from the north or south, if the cue card was east or west, or if the rat entered $0^{\circ}$ or $180^{\circ}$ away from the cue card. One crucial difference between the present study and that of Sharp et al. (1990) is that during training, we placed the rat into the cylinder from all directions, whereas Sharp et al. placed the rat from a single direction. In the present study, we also found no evidence that the fields were bound to some uncontrolled cue outside the cylinder. Overall, we could determine no aspect of the recording procedure or environment that would predict whether a transition would occur in a given session. 


\section{Thalamic Head Direction Cell}
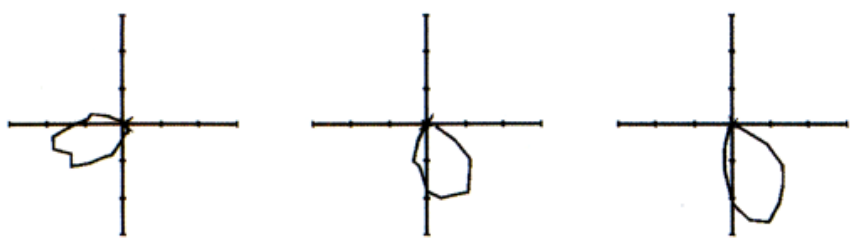

\section{CA1 Place Cells}

\section{Cell 1}
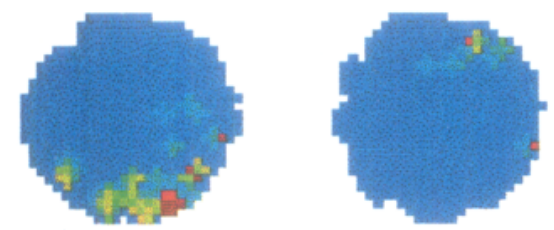

Cell 2
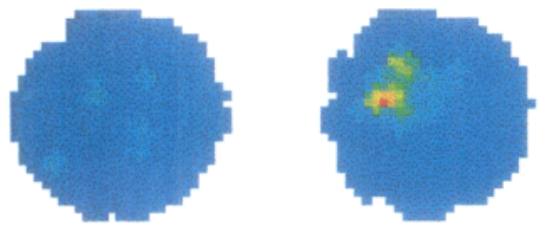

Cell 3

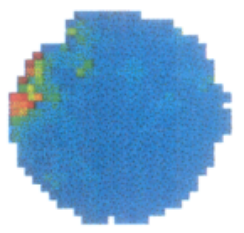

Min 1-4

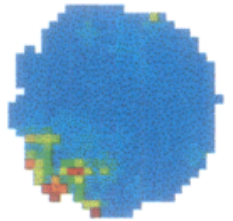

Min 5-8
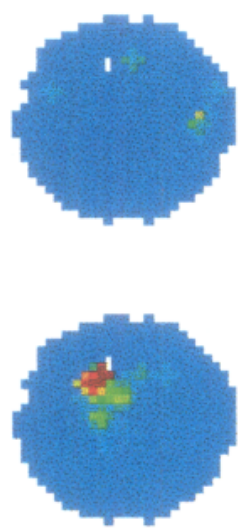

Rat

Before restraint

3803
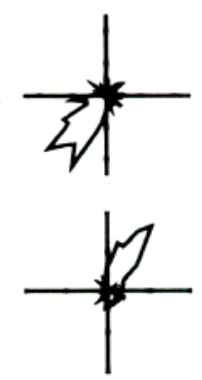

3851

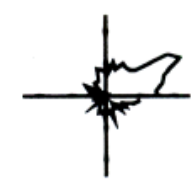

3884

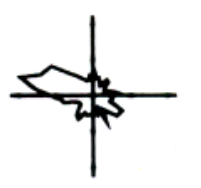

3912
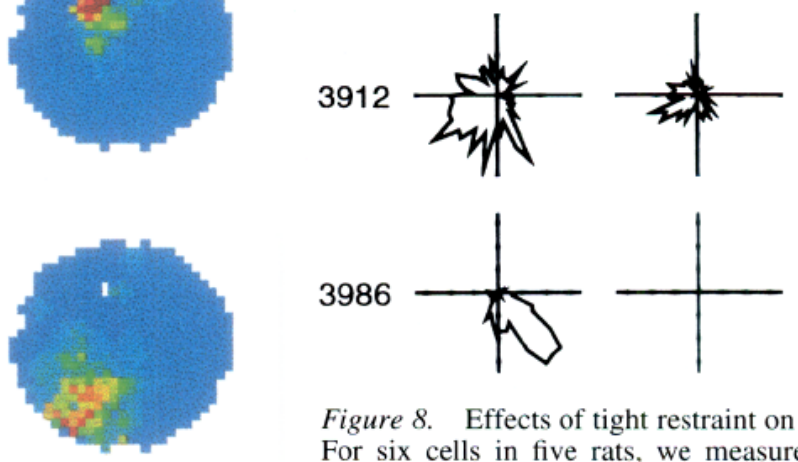

Min 9-12
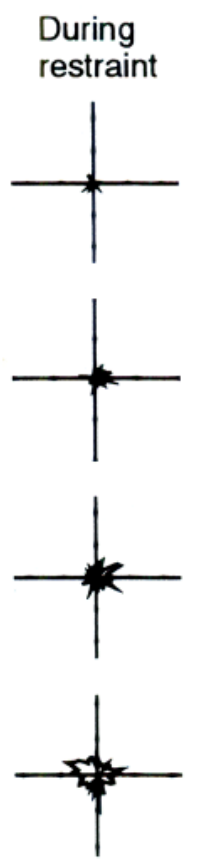

3986
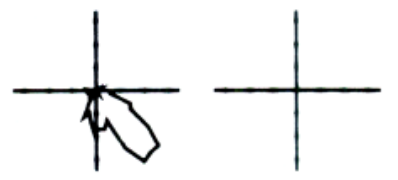

Figure 7. Rotation of a head direction cell and partial remapping of the hippocampal representation within the same recording session. The head direction tuning curve and the firing rate maps are broken down into 4 min segments. The head direction cell initially fired west during the first $4 \mathrm{~min}$, then rotated about $90^{\circ}$ counterclockwise until it fired south, where it remained for the final $8 \mathrm{~min}$ of the session. Place cell $1 \mathrm{had}$ a field against the south wall during the first $4 \mathrm{~min}$, but the field disappeared when the head direction cell rotated. At the same time, place cell 2 developed a field, and place cell 3 rotated with the head direction cell. Rat 3918: maximum firing rates for place cells in spikes/ sec, all time periods, cell 1,5 ; cell 2, 8; cell 3, 14. Head direction cell axes, all time periods, \pm 30 spikes $/ \mathrm{sec}$.

\section{Effects of restraint on head direction cells}

Foster et al. (1989) demonstrated an influence of motor set on the firing of hippocampal place cells. They trained rats to accept tight restraint by wrapping them in a towel to make the rats immobile, and they showed that place cells became virtually silent under these conditions, even when the rat was in the place field of the cell. Cells regained their place fields immediately when the restraint was removed, even if the rat remained immobile. To test further the relationship between hippocampal place cells and head direction cells, we performed this same experiment on six head direction cells from five rats. All six cells greatly reduced their firing rates when the rat was restrained, in some cases shutting off completely (Fig. 8); the fir-

After
restraint

After restraint 2
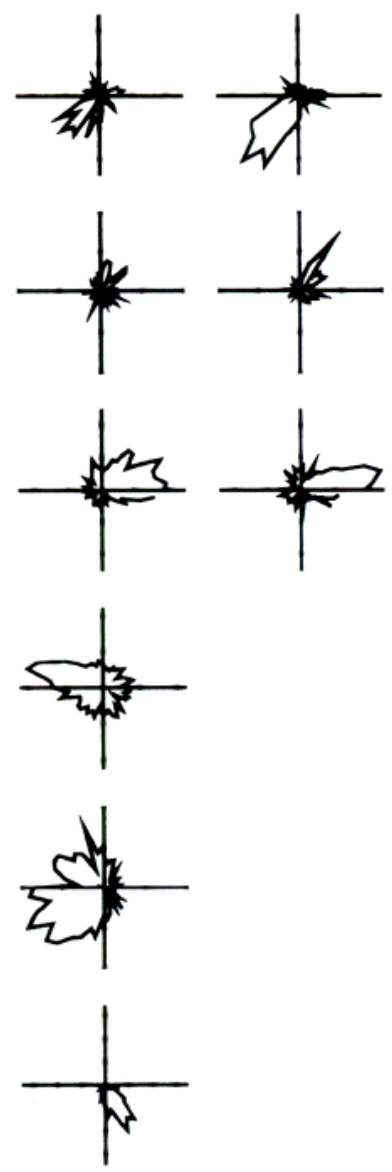

Figure 8. Effects of tight restraint on the firing of head direction cells. For six cells in five rats, we measured the directional tuning curves while the rat sat on a narrow pedestal and was passively rotated. We then wrapped the rat securely in a towel, such that it was incapable of moving, and remeasured the directional tuning curve. The head direction cells were either completely silenced or were greatly attenuated. When the restraint was removed, the cells mostly returned to their original firing rates, although it sometimes took minutes for the cells to reach their maximum rates. Axis scales, all conditions, in spikes/sec: rat $3803, \pm 25$; rat $3851(1), \pm 40$; rat $3851(2), \pm 50$; rat $3884, \pm 45$; rat $3912, \pm 40$; rat $3986, \pm 70$.

ing rate increased again when the restraint was removed. Sometimes the firing rate after restraint did not immediately reach its prerestraint level, but over time the firing rate usually recovered its initial magnitude. The rats were inclined to groom right after the towel was removed, and this difference in firing rate before and after restraint may be a reflection of this change in their behavior or internal state. Overall, though, it appears that the thalamic head direction system shuts down, or greatly diminishes its firing rates, when the rat is restrained. Similar, but weaker, effects were reported by Markus et al. (1990) and Taube et al. (1990b) in the postsubiculum; these experimenters did not restrain their rats very tightly (they held them in their hands), which probably explains the difference in the strength of the effect. The results are consistent, though, in demonstrating that head direction cells, like hippocampal place cells, are modulated by motor set or other behavioral state variables, thus reinforcing the strong links between these two systems. 


\section{Discussion}

Effects of prior training experience on control of place cells by visual cues

Previous studies of hippocampal place cells indicated that place fields were under the control of external sensory cues. O'Keefe and Conway (1978) showed that place fields maintained their positions relative to the distal cues when an elevated $\mathrm{T}$ maze and the cues were rotated relative to each other. O'Keefe and Speakman (1987) trained rats to locate a food reward on one arm of a four-arm radial maze based on an array of "controlled cues" enclosed within a black circular curtain. The rats learned to follow the controlled cues to find the reward, and the place fields also followed the rotation of the cues (although there remained some influence of the uncontrolled background cues; see below). Muller, Kubie, and their colleagues introduced the much simpler behavioral task and experimental apparatus adopted in the present study, in which rats searched for food pellets dropped randomly in an enclosed apparatus that had only a single salient visual cue, typically a large white cue card. In their experiments, when the card was rotated in between sessions, the place cells and head direction cells almost always followed the rotation (Muller and Kubie, 1987; Taube et al., 1990b; Bostock et al., 1991; but see Rotenberg et al., 1993; also Wiener et al., 1992).

The results from the present study demonstrate that the cue control over hippocampal place fields is not an inherent property of the system, even when there is only one salient cue available to the rat. Rather, the degree to which the cue controls the locations of place fields depends strongly on the prior experience of the animal. In particular, it appears that the rats have to learn that the visual cue is a stable directional reference for the cue to have control over the fields; alternatively, the cue may have control by default, unless the rat learns that it is not a stable cue. The disorientation training rats of this study never had the explicit experience of the cue card as a stable cue, for the disorientation procedure and the experimental control over other potential cues made it possible for the rat to perceive the cue as bcing rotated from trial to trial. The nondisorientation training rats, however, did receive the explicit information that the cue card was a stable directional reference. When these two groups were both tested under disorientation conditions, the cue had much stronger control over the place fields in those rats that had the prior explicit experience of the cue card as a stable landmark.

The effect of the disorientation training on cue control is somewhat counterintuitive. As mentioned in the introductory remarks, behavioral studies from other laboratories and previous physiological studies from this laboratory have used the disorientation procedure in an effort to enhance the control of visual cues over the rat's behavior and the cellular firing properties. The logic was that the disoriented rats would learn that their path integration system was an unreliable predictor of reward location and/or direction, and they would thus be forced to rely upon the reliable visual cues. However, if the model proposed by McNaughton et al. (1991) is correct (see introductory remarks), the rats will learn to disregard the visual cues, precisely because they have been disoriented, for they will perceive the cues as being unstable and will be more likely to follow their internal direction sense. Although the results of the present experiment support this interpretation, it is unclear whether the cue card would have had more control if it had been necessary for the performance of some behavioral task or if there had been multiple visual cues. We believe this is unlikely, since Cheng
(1986) has shown that disoriented rats rely more on the geometric shape of a rectangular environment to find buried food than they do on the locations of multiple visual cues; even though the visual cues were the only reliable predictors of food location, the rats dug for food in the geometrically opposite location of the rectangle almost as often as they dug in the correct location. When the rats were not disoriented, however, they alInost always dug in the correct location (Margules and Gallistel, 1988). Interestingly, human children also rely on geometric information over visual cues when they are disoriented, even though only the visual cues predict the reward site, whereas adults learn to use the visual cues to disambiguate the symmetrical geometry of the environment (Hermer and Spelke, 1994).

\section{Hippocampal place cells and thalamic head direction cells}

Under the recording conditions of the present experiment, hippocampal place cells and thalamic head direction cells werc strongly coupled, comprising a unitary system for spatial orientation. It is not known whether one system drives the other, or whether they are both driven by some other system, although Mizumori and Williams (1992) showed that inactivation of the lateral dorsal nucleus (LDN)--another thalamic nucleus containing head direction cells - can disrupt hippocampal place fields and cause spatial learning deficits. One possibility is that both sets of cells mutually influence each other. Under certain conditions, the head direction system might determine the orientation of the hippocampal spatial map (as hypothesized in the present study), whereas under other conditions, the hippocampal map might orient the head direction system.

It is also not known whether the strong coupling between the systems observed in the present study extends to other recording environments or behavioral tasks. Are there behavioral situations in which the two systems can be decoupled, temporarily or permanently? If so, do the different systems of head direction cells (e.g., ADN vs LDN vs postsubiculum) behave differently, or are they always in synchrony? For instance, what would happen in a situation in which the rat is required to keep track of two frames of reference in a given task (e.g., a local maze-bound frame and a global laboratory frame)? Would place cells and head direction cells be bound to one frame or the other, or would they decouple, some cells bound to one reference frame and some to the other? The answers to these important questions will help us to understand the nature of the interactions between the hippocampal representation and the internal direction sense, and how these interactions affect the rat's navigational abilities.

\section{Hippocampal remapping}

One of the intriguing results of this study was the partial remapping of the hippocampal place representation seen in some rats, both between and within sessions, when the head direction cells rotated away from the cue card. This effect is similar to the remapping reported by Bostock et al. (1991) when they replaced the rat's familiar white cue card with a novel black card and observed the hippocampus develop independent representations of the two conditions over time. O'Keefe and Speakman (1987) also showed a similar effect in that some cells in their study had place fields only when their controlled cues were in a particular orientation relative to the background cues. The present results show that this kind of remapping can occur even in the absence of any change in the sensory environment. All that is required is that the animal perceive that the environment has been somehow altered (e.g., rotated) and the hippocampus 
may develop a new representation of the altered environment. Other evidence demonstrates that such remappings can result from a change in the behavioral task of the animal, with no real or imaginary change in the sensory environment (Qin et al., 1994). The rules governing the process by which the hippocampus creates new representations of similar (or identical) environments are not well understood. What is known, however, clearly opens up many questions about what it is that is represented by place cell firing. One prominent view has been that place fields represent the constellation of sensory cues impinging on the animal's sensorium at a given location in space (McNaughton et al., 1989b). Such an account would have trouble explaining the rotation or remapping of place fields when there is no change in the sensory cues in the environment. One possibility is that place cells represent only the stable, salient cues in the environment. Another possibility is that the hippocampus can form two or more separate, context-dependent representations of the same environment, and that each cell is capable of representing different sets of cues in each context (just as it is capable of representing different cues in different environments). Thus, a cell will fire at one location (representing one set of cues) when the cue card is perceived east (context 1) and will fire at another location (representing a different set of cues) when the cue card is perccived west (context 2). Alternatively, the whole notion of place cells representing constellations of sensory cues may have to be replaced by models emphasizing path integration in the development of place fields and concepts such as the encoding of space in terms of vectors bound to salient landmarks (O'Keefe, 1991; Touretzky et al., 1993; McNaughton et al., 1994). Additional experiments, like the present study, which addiess the factors influencing place cell firing and plasticity may provide the data necessary to develop viable models of hippocampal representations and function.

\section{References}

Batschelet E (1981) Circular statistics in biology. New York: Academic.

Biegler R, Morris RGM (1993) Landmark stability is a prerequisite for spatial but not discrimination learning. Nature 361:631-633.

Bostock E, Muller RU, Kubie JL (1991) Experience-dependent modifications of hippocampal place cell firing. Hippocampus 1:193-206.

Chen LL, Lin L, Green EJ, Barnes CA, McNaughton BL (1994a) Headdirection cells in the rat posterior cortex. I. Anatomical distribution and behavioral modulation. Exp Brain Res, in press.

Chen LL, Lin L, Barnes CA, McNaughton BL (1994b) Head-direction cells in the rat posterior cortex. II. Contributions of visual and ideothetic information to the directional firing. Exp Brain Res, in press.

Cheng K (1986) A purely geometric module in the rat's spatial representation. Cognition 23:149-178.

Collett TS, Cartwright BA, Smith BA (1986) Landmark learning and visuo-spatial memories in gerbils. J Comp Physiol (A) 158:835-851.

Etienne AS (1992) Navigation of a small mammal by dead reckoning and local cues. Curr Dir Psychol Sci 1:48-52.

Etienne AS, Lambert SJ, Reverdin B, Teroni E (1993) Learning to recalibrate the role of dead reckoning and visual cues in spatial navigation. Anim Iearn Rehav 21:266-280.

Foster TC, Castro CA, McNaughton BL (1989) Spatial selectivity of hippocampal neurons: dependence on preparedness for movement. Science 24:1580-1582.

Hermer L, Spelke ES (1994) A geometric process for spatial reorientation in young children. Nature 370:57-59.

Kuierim JJ, McNaughton BL, Duffield C, Bliss J (1993) On the binding of hippocampal place fields to the inertial orientation system. Soc Neurosci Abstr 19:795.

Kubie JL, Muller RU, Bostock E (1990) Spatial firing properties of hippocampal theta cells. J Neurosci 10:1110-1123.

Margules J, Gallistel CR (1988) Heading in the rat: determination by environmental shape. Anim Learn Behav 16:404 410.

Markus EJ, McNaughton BL, Barnes CA, Green JC, Meltzer J (1990)
Head direction cells in the dorsal presubiculum integrate both visual and angular velocity information. Soc Neurosci Abstr 16:441.

McNaughton BL, O'Keefe J, Barnes CA (1983a) The stereotrode: a new technique for simultaneous isolation of several single units in the central nervous system from multiple unit records. J Neurosci Methods 8:391397.

McNaughton BL, Barnes CA, O'Keefe J (1983b) The contributions of position, direction, and velocity to single unit activity in the hippocampus of freely-moving rats. Exp Brain Res 52:41-49.

McNaughton BL, Barnes CA, Meltzer J, Sutherland RJ (1989a) Hippocampal granule cells are necessary for spatial learning but not for spatially-selective pyramidal cell discharge. Exp Brain Res 76:485-496.

McNaughton BL, Leonard B, Chen L (1989b) Cortical-hippocampal interactions and cognitive mapping: a hypothesis based on reintegration of the parietal and inferotemporal pathways for visual processing. Psychobiology 17:230-235.

McNaughton BL, Chen LL, Markus EJ (1991) “Dead reckoning," landmark learning, and the sense of direction: a neurophysiological and computational hypothesis. J Cognit Neurosci 3:190-202.

McNaughton BL, Knierim JJ, Wilson MA (1994)Vector encoding and the vestibular foundations of spatial cognition: neurophysiological and computational mechanisms. In: The cognitive neurosciences (Gazzaniga M, ed), pp 585-595. Boston: MIT Press.

Mittelstaedt ML, Mittelstaedt H (1980) Homing by path integration in a mammal. Naturwissenschaften 67:566-567.

Mizumori SJY, Williams JD (1992) Interdependence of hippocampal and lateral dorsal thalamic representations of space. Soc Neurosci Abstr 18: 708.

Mizumori SJY, Williams JD (1993) Directionally selective mnemonic properties of neurons in the lateral dorsal nucleus of the thalamus of rats. J Neurosci 13:4015-4028.

Muller RU, Kubie JL (1987) The effects of changes in the environment on the spatial firing of hippocampal complex-spike cells. J Neurosci 77 : 1951-1968.

Muller RU, Kubic JL, Ranck JB Jr (1987) Spatial firing patterns of hippocampal complex-spike cells in a fixed environment. J Neurosci 77 : 1935-1950.

O'Keefe J (1991) An allocentric spatial model for the hippocampal cognitive map. Hippocampus 1:230-235.

O'Keefe J, Conway DH (1978) Hippocampal place units in the freely moving rat: why they fire where they fire. Exp Brain Res 31:573-590.

O'Keefe J, Speakman A (1987) Single unit activity in the rat hippocampus during a spatial memory task. Exp Brain Res 68:1-27.

Qin Y, Markus EJ, McNaughton BL, Barnes CA (1994) Hippocampal place fields change with navigational context. Soc Neurosci Abstr 20: 1207.

Ranck JB Jr (1973) Studies on single neurons in dorsal hippocampal formation and septum in unrestrained rats. Part 1. Behavioral correlates and firing repertoires. Exp Neurol 41:461-531.

Recce ML, O'Keefe J (1989) The tetrode: an improved technique for multi-unit extracellular recording. Soc Neurosci Abstr 15:1250.

Rotenberg A, Kubie J, Muller R (1993) Variable coupling between a stimulus object and place cell firing fields. Soc Neurosci Abstr 19:357.

Sharp PE, Kubie JL, Muller RU (1990) Firing properties of hippocampal neurons in a visually symmetrical environment: contributions of multiple sensory cues and mnemonic processes. J Neurosci 10:3093-3105.

Skaggs WE, McNaughton BL, Gothard KM, Markus EJ (1993) An information-theoretic approach to deciphering the hippocampal code. In: Advances in neural information processing systems (Hanson SJ, Cowan JD, Giles CL, eds), pp 1030-1037. San Mateo, CA: Kaufman.

Taube JS (1992) Qualitative analysis of head-direction cells recorded in the rat anterior thalamus. Soc Neurosci Abstr 18:708.

Taube JS, Muller RU, Ranck JB Jr (1990a) Head direction cells recorded from the postsubiculum in freely moving rats. I. Description and quantitative analysis. J Neurosci 10:420-435.

Taube JS, Muller RU, Ranck JB Jr (1990b) Ilead direction cells recorded from the postsubiculum in freely moving rats. II. Effects of environmental manipulations. J Neurosci 10:436-447.

Touretzky DS, Redish AD, Wan HS (1993) Neural representation of space using sinusoidal arrays. Neural Computation 5:869-884.

Wiener SI (1993) Spatial and behavioral correlates of striatal neurons in rats performing a self-initiated navigation task. J Neurosci 13:3802-3817.

Wiener SI, Garcia R, Berthoz A (1992) Spatial reference frames of hippocampal place cells in rats. Soc Neurosci Abstr 18:706.

Wilson MA, McNaughton BL (1993) Dynamics of the hippocampal ensemble code for space. Science 261:1055-1058. 